\title{
Anxiety and Caffeine Consumption in People With Anxiety Disorders
}

\author{
Myung Ae Lee, Oliver G. Cameron, and John F. Greden
}

Received December 12, 1984; revised version received April 29, 1985; accepted May 14, 1985.

\begin{abstract}
Forty-three anxiety disorder patients ( $D S M$ - $I I I)$ who completed the Hopkins Symptom Checklist (SCL-90-R) and a caffeine questionnaire were compared to 124 medical inpatients. Eighty-four percent of the anxious patients were low caffeine consumers $(0-249 \mathrm{mg} /$ day) compared to $41 \%$ of medical inpatients; $65 \%$ of anxiety patients consumed $<100 \mathrm{mg} / \mathrm{day}$. In anxiety patients, there were no significant correlations between subscale scores of the SCL-90-R and amount of caffeine consumption. Patients who consumed $<100 \mathrm{mg} /$ day did not differ on anxiety subscale scores of the SCL-90-R from those who consumed more. However, patients who reported becoming anxious in response to drinking coffee had higher SCL-90-R anxiety subscale scores than patients who did not, even though their daily consumption was not different. It appears that anxiety disorder patients have increased caffeine sensitivity which leads to decreased consumption.
\end{abstract}

Key Words. Caffeine, anxiety disorders.

Caffeine is known to produce anxiety (Greden et al., 1978; Gilliland and Andress, 1981; Rapoport et al., 1981; Victor et al., 1981) and even panic attacks (Uhde et al., 1984). In normal adults (Gilliland and Andress, 1981) and psychiatric inpatients (Greden et al, 1978), state and/or trait anxiety scores were higher in moderate to high caffeine consumers, and in medical inpatients (Victor et al., 1981) and normal adults (Rapoport et al., 1981), high caffeine consumers were more sensitive to caffeine intake (i.e., became anxious). However, somatic symptoms seem to be reported more frequently in low consumers (Victor et al., 1981; Rapoport et al., 1981). Boulenger et al. (1984) reported a significant positive correlation between trait anxiety and daily caffeine consumption, and increased sensitivity to caffeine in panic disorder patients but not in normal controls or patients with a major depressive disorder, even though daily caffeine consumption was not significantly different between these groups.

Pharmacologically, caffeine has been reported to antagonize some of the effects of benzodiazepines (Polc et al., 1981; File et al., 1982; Mattila et al., 1982) and to block benzodiazepine and adenosine receptor binding (Boulenger et al., 1982; Snyder and Sklar, 1984). Acute administration of caffeine increases blood pressure, and plasma and urinary catecholamines (Robertson et al., 1978; Patwadhan et al., 1980) as well as plasma cortisol concentration (Uhde et al., 1984), but chronic administration does not

\footnotetext{
Myung Ae Lee, M.D., is Fellow, Anxiety Disorders Program; Oliver G. Cameron, M.D., Ph.D., is Assistant Professor of Psychiatry; and John F. Greden, M.D., is Chairman, Department of Psychiatry, University of Michigan. (Reprint requests to Dr. M.A. Lee, Dept. of Psychiatry, Box 011, University of Michigan Hospitals, 1405 E. Ann St., Anil Arbor, MI 48109, USA.)
}

0165-1781/85/\$03.30 $\odot 1985$ Elsevier Science Publishers B.V. 
increase plasma and urinary catecholamines (Robertson et al., 1981). Caffeine also increased norepinephrine utilization associated with decreases in $\beta$-adrenergic receptors in rat forebrain (Goldberg et al., 1982).

Perhaps because of these pharmacological actions, anxiety disorder patients seem to consume less caffeine or even stop consuming caffeine to avoid intensification of anxiety. Boulenger et al. (1984) suggested that the positive correlation they observed between trait anxiety and caffeine consumption was not due to patients' "selftreatment," a pattern that has been reported for some depressed patients and for some people with caffeine-withdrawal headache (Greden et al., 1978, 1980). Thus, in anxiety disorder patients, it is possible that the relationship between daily caffeine consumption and level of anxiety may be different from those previously reported for normal adults, and medical and psychiatric inpatients. We examined these issues further in anxiety disorder patients, hypothesizing that anxious individuals would have lower daily caffeine consumption and be more sensitive to the anxiety-provoking effects of caffeine than other people.

\section{Methods}

Forty-three outpatient subjects who met DSM-III (American Psychiatric Association, 1980) criteria for anxiety disorder completed the Hopkins Symptom Checklist (SCL-90-R) (5-point scale: $0=$ "not at all" through $4=$ "extremely") (Derogatis, 1977) and a caffeine questionnaire designed by one of us (J.F.G.). The questionnaire assessed amount of daily consumption of caffeine-containing beverages and drugs, symptom profiles in response to drinking a cup of coffee (see Table 1), and use of minor tranquilizers and other medications; details of this questionnaire have been reported elsewhere (Victor et al., 1981). Amount of daily caffeine consumption from approximately 25 sources was calculated, and correlations between caffeine

Table 1. Symptom profile comparison between anxiety disorder patients and
medical inpatients, and between $<100 \mathrm{mg}$ and $>100 \mathrm{mg}$ groups of anxiety
disorder patients

\begin{tabular}{|c|c|c|c|c|}
\hline \multirow[b]{3}{*}{ Symptoms } & \multirow{3}{*}{$\begin{array}{c}\begin{array}{c}\text { Anxiety } \\
\text { disorders1 }\end{array} \\
(n=34)(\%)\end{array}$} & \multirow{3}{*}{$\begin{array}{c}\begin{array}{c}\text { Medical } \\
\text { inpatients } 1\end{array} \\
(n=51)(\%)\end{array}$} & \multicolumn{2}{|c|}{ Anxiety disorders } \\
\hline & & & \multirow{2}{*}{$\begin{array}{c}<100 \mathrm{mg} \\
(n=25)(\%)\end{array}$} & \multirow{2}{*}{$\begin{array}{c}>100 \mathrm{mg} \\
(n=14)(\%)\end{array}$} \\
\hline & & & & \\
\hline Anxiety & 64.7 & 21.52 & 72.0 & 50.0 \\
\hline Diarrhea & 11.8 & 16.5 & 12.0 & 14.3 \\
\hline Diuresis & 73.5 & 59.5 & 72.0 & 78.6 \\
\hline Headache & 9.1 & 13.0 & 12.0 & 7.1 \\
\hline Lightheadedness & 23.5 & 13.9 & 28.0 & 14.3 \\
\hline Palpitation & 35.3 & 25.3 & 40.0 & 28.6 \\
\hline Stomach pain & 23.5 & 27.8 & 24.0 & 21.4 \\
\hline Spot in front of eye & 2.9 & 3.8 & 4.0 & 7.1 \\
\hline Tachycardia & 44.1 & 28.2 & 60.0 & 28.63 \\
\hline Tachypnea & 23.5 & 12.4 & 28.0 & 28.6 \\
\hline Tremulousness & 35.3 & 16.44 & 44.0 & 14.3 \\
\hline
\end{tabular}

In order to make groups comparable, only low consumers $(<250 \mathrm{mg} /$ day) are included.

2. $\chi^{2}=16.75, p<0.001$.

3. $x^{2}=4.01, p<0.05$

4. $\chi^{2}=4.36, p<0.05$ 
consumption and subscale scores on the SCL-90-R were examined. Student's $t$ test (two-tailed) was used to compare mean differences between patient groups. Medical inpatients $(n=124)$ who responded to the same caffeine questionnaire and who were free from any known psychiatric illness or treatment (data for this group were reported previously by Victor et al., 1981) were compared with the anxiety patients (by $\chi^{2}$ ) in distribution of daily caffeine consumption and reported symptom profiles in response to drinking a cup of coffee.

\section{Results}

Demographic Data and Caffeine Consumpion. The anxiety patients included 16 males and 27 females. Their mean age was 34.4 (SD 10.0) years. Diagnostically, 34 had panic disorder or agoraphobia with panic attacks (PA group); the remaining nine included six with obsessive-compulsive disorder or generalized anxiety disorder, and three with simple or social phobia (non-PA group). Mean daily caffeine consumption of all anxiety patients was 141.7 (SD 215.7 ) $\mathrm{mg}$ /day. Distribution of daily caffeine consumption showed that 28 patients $(65 \%)$ consumed $\leqslant 100 \mathrm{mg} /$ day (roughly equivalent to one cup of coffee), five (12\%) consumed $100-199 \mathrm{mg} /$ day, four $(9 \%)$ consumed 200-299 mg/day, and six (14\%) consumed $>300 \mathrm{mg} /$ day. Daily caffeine consumption did not differ between PA and non-PA groups (137.4 \pm SD 218.2 $\mathrm{mg} /$ day for PA vs. $158.2 \pm \mathrm{SD} 217.8 \mathrm{mg} /$ day for non-PA, $t=0.26, \mathrm{NS}$ ).

Responses to Drinking a Cup of Coffee. Thirty-nine anxiety patients completed this item (30 were PA, nine were non-PA). In the total sample, order of frequency of symptoms in response to a cup of coffee were diuresis $(74 \%)$, anxiety $(64 \%)$, tachycardia (49\%), palpitations (36\%), and tremulousness (33\%). Twenty-five patients responded that a cup of coffee made them anxious. Among them, 23 were PA and 2 were non-PA; this difference was significant $\left(\chi^{2}=10.30, p<0.001\right)$.

Anxiety patients were divided into two groups $--<100 \mathrm{mg} /$ day vs. $>100 \mathrm{mg} /$ day of caffeine consumption. A $100 \mathrm{mg}$ cutoff was used because this is the amount contained in approximately one cup of coffee. Symptom profiles were compared between the $<$ $100 \mathrm{mg}$ and the $>100 \mathrm{mg}$ groups. Frequency of developing anxiety was not different between groups $\left(\chi^{2}=1.94\right.$, NS), but somatic symptoms such as tachycardia, palpitation, tremulousness, and lightheadedness tended to develop more in the $<100$ mg group, and tachycardia reached statistical significance (Table 1).

Daily Caffeine Consumption and the SCL-90-R. There were no significant correlations between amount of daily caffeine consumption and any of the subscale scores of the SCL-90-R. To compare mean score differences of the SCL-90-R, subjects were divided in two different ways: (1) $<100 \mathrm{mg}$ group vs. $>100 \mathrm{mg}$ group (as above); and (2) development of anxiety in response to coffee consumption (caffeine-sensitive group vs. caffeine-nonsensitive group). There were no differences in mean SCL-90-R subscale scores between the $<100 \mathrm{mg}$ group and the $>100 \mathrm{mg}$ group. However, when subjects were divided by response to caffeine consumption, the caffeine-sensitive group had significantly higher SCL-90-R subscale scores in somatization, anxiety, and phobic anxiety than the caffeine-nonsensitive group (Table 2). There were no differences in caffeine consumption or use of minor tranquilizers between these groups. 
Table 2. SCL-90-R differences between caffeine-sensitive and caffeinenonsensitive group in total sample and in PA group

\begin{tabular}{|c|c|c|c|c|}
\hline \multirow[b]{2}{*}{$\begin{array}{l}\text { SCL-90-R } \\
\text { Scales } \\
\text { (mean } \pm \text { SD) }\end{array}$} & \multicolumn{2}{|c|}{ Total patients $(n=39)$} & \multicolumn{2}{|c|}{ PA group only $(n=30)$} \\
\hline & $\begin{array}{c}\text { Caffeine- } \\
\text { sensitive } \\
(n=25)\end{array}$ & $\begin{array}{l}\text { Caffeine- } \\
\text { nonsensitive } \\
(n=14)\end{array}$ & $\begin{array}{l}\text { Caffeine- } \\
\text { sensitive } \\
(n=23)\end{array}$ & $\begin{array}{c}\text { Caffeine- } \\
\text { nonsensitive } \\
(n=7)\end{array}$ \\
\hline Somatization & $1.46 \pm 0.68$ & $0.82 \pm 0.701$ & $1.56 \pm 0.61$ & $1.19 \pm 0.73$ \\
\hline $\begin{array}{l}\text { Obsessive- } \\
\text { compulsive }\end{array}$ & $1.72 \pm 0.74$ & $1.49 \pm 0.84$ & $1.75 \pm 0.76$ & $1.53 \pm 0.79$ \\
\hline $\begin{array}{l}\text { Interpersonal } \\
\text { sensitivity }\end{array}$ & $1.83 \pm 0.90$ & $1.61 \pm 1.03$ & $1.82 \pm 0.87$ & $1.44 \pm 0.83$ \\
\hline Depression & $2.02 \pm 0.75$ & $1.83 \pm 0.91$ & $2.07 \pm 0.73$ & $1.87 \pm 0.89$ \\
\hline Anxiety & $2.45 \pm 0.73$ & $1.69 \pm 0.982$ & $2.51 \pm 0.67$ & $1.83 \pm 0.833$ \\
\hline Hostility & $1.10 \pm 0.83$ & $1.20 \pm 0.85$ & $1.13 \pm 0.86$ & $1.12 \pm 0.91$ \\
\hline Phobic anxiety & $2.19 \pm 0.84$ & $1.39 \pm 0.104$ & $2.28 \pm 0.82$ & $1.80 \pm 0.90$ \\
\hline Paranoid ideation & $1.20 \pm 0.94$ & $1.04 \pm 0.84$ & $1.20 \pm 0.95$ & $0.93 \pm 0.98$ \\
\hline Psychoticism & $1.00 \pm 0.57$ & $0.91 \pm 0.72$ & $1.00 \pm 0.56$ & $0.89 \pm 0.76$ \\
\hline $\begin{array}{l}\text { Global severity } \\
\text { index }\end{array}$ & $1.68 \pm 0.53$ & $1.34 \pm 0.70$ & $1.72 \pm 0.52$ & $1.42 \pm 0.71$ \\
\hline $\begin{array}{l}\text { Positive symptom } \\
\text { distress index }\end{array}$ & $2.39 \div 0.54$ & $2.10 \pm 0.59$ & $2.43 \pm 0.52$ & $2.03 \pm 0.53$ \\
\hline
\end{tabular}

1. $t=2.79, p<0.01$.

2. $t=2.76, p<0.01$.

$3 . t=2.23, p<0.05$

4. $t=3.53, p<0.01$.

Since the PA group, who represented a greater percentage of caffeine-sensitive patients, had higher SCL-90-R scores in anxiety, somatization, and phobic anxiety than the non-PA group, the PA group was examined separately to eliminate possible effects due to diagnosis (Table 3). As was true of the total sample, there were no significant correlations between caffeine consumption and SCL-90-R scores and no

Table 3. SCL-90-R differences between PA and non-PA groups

\begin{tabular}{lcc} 
SCL-90-R Scales (mean \pm SD) & $\begin{array}{c}\text { PA group } \\
(\boldsymbol{n}=\mathbf{3 0})\end{array}$ & $\begin{array}{c}\text { Non-PA group } \\
(\boldsymbol{n}=\mathbf{9})\end{array}$ \\
\hline Somatization & $1.47 \pm 0.64$ & $0.42 \pm 0.421$ \\
Obsessive-compulsive & $1.70 \pm 0.76$ & $1.43 \pm 0.84$ \\
Interpersonal sensitivity & $1.73 \pm 0.86$ & $1.83 \pm 1.23$ \\
Depression & $2.02 \pm 0.76$ & $1.73 \pm 0.96$ \\
Anxiety & $2.35 \pm 0.75$ & $1.58 \pm 1.112$ \\
Hostility & $1.12 \pm 0.86$ & $1.17 \pm 0.78$ \\
Phobic anxiety & $2.17 \pm 0.85$ & $1.03 \pm 0.853$ \\
Paranoid ideation & $1.14 \pm 0.95$ & $1.15 \pm 0.66$ \\
Psychoticism & $0.98 \pm 0.60$ & $0.92 \pm 0.73$ \\
Global severity index & $1.65 \pm 0.57$ & $1.24 \pm 0.69$ \\
Positive symptom distress index & $2.34 \pm 0.55$ & $2.11 \pm 0.63$ \\
\hline
\end{tabular}

1. $t=4.61, p<0.001$

2. $t=2.41, p<0.05$.

3. $t=3.53, p<0.01$ 
difference in mean SCL-90-R subscale scores between the $<100 \mathrm{mg}$ and the $>100 \mathrm{mg}$ group. However, even among PA patients only, anxiety subscale score differences persisted between the caffeine-sensitive and the caffeine-nonsensitive groups-being higher in the caffeine-sensitive group; but no differences in somatization or phobic anxiety were observed (Table 2). There were no differences in caffeine consumption or use of minor tranquilizers between these two PA groups.

Comparison With Medical Inpatients. Both anxiety and medical inpatient groups were divided into three strata by using cutoff values of daily caffeine consumption similar to a prior report (Victor et al., 1981): low consumer (0-249 mg/day), moderate consumer (250-749 mg/day), and high consumer $(\geqslant 750 \mathrm{mg} /$ day). Their distribution of caffeine consumption was significantly different $\left(\chi^{2}=23.37, p<0.001\right)$. In the anxiety disorders group, $84 \%$ were low consumers, $14 \%$ were moderate consumers, and $2 \%$ were high consumers; in contrast, $41 \%$ of medical inpatients were low consumers, $43 \%$ were moderate consumers, and $16 \%$ were high consumers. Thus, anxious patients consumed significantly less caffeine. Age distribution, which has been reported to affect caffeine consumption (Victor et al., 1981), was not different between these groups.

Since the majority of anxiety patients were low consumers, symptom profiles in response to drinking a cup of coffee were compared between anxious patients and medical inpatients for the low consumer groups only. Anxiety disorder patients reported a significantly higher rate of anxiety and tremulousness in response to coffee consumption compared to the medical inpatient group. No other symptoms were different in these groups (Table 1).

\section{Discussion}

Two-thirds of the anxiety patients in this study consumed $<100 \mathrm{mg}$ of caffeine/day; when compared to medical inpatients, twice the number of anxiety patients consumed $<250 \mathrm{mg} /$ day. This difference was not due to inpatient vs. outpatient status because questionnaires asked specifically about the amount of caffeine consumption before admission to the hospital. This level of consumption was also less than that of previously reported psychiatric inpatients who were similar to the medical inpatient group (Victor et al., 1981).

Among low caffeine consumers only, three times as many anxiety disorder patients as medical inpatients reported anxiety symptoms in response to coffee consumption. Thus, anxiety patients were more sensitive to caffeine than were medical inpatients, even though their daily caffeine consumption was in the same range. In this sample of anxiety patients, the SCL-90-R anxiety subscale score did not differ between high $(>$ $100 \mathrm{mg} / \mathrm{day}$ ) and low ( $<100 \mathrm{mg} /$ day) caffeine consumers. However, anxiety level was different if compared according to patients' ratings of their response to drinking a cup of coffee; the caffeine-sensitive patients had higher SCL-90-R anxiety subscale scores than the caffeine-nonsensitive patients, even though the amount of daily caffeine consumption did not differ between the two groups.

The difference in anxiety scores between caffeine-sensitive and nonsensitive patients seems not to be due to overrepresentation of PA patients in the caffeine-sensitive 
group since, even if only PA patients are evaluated, this difference in anxiety in response to caffeine consumption still remained, suggesting that the caffeine-sensitive group does have a higher anxiety level than the caffeine-nonsensitive group. On the other hand, differences in somatization and phobic anxiety in the total sample did seem to be due to the greater percentage of PA patients in the caffeine-sensitive group. This finding is different from prior studies with college students (Gilliland and Andress, 1981) and psychiatric inpatients (Greden et al., 1978), where only moderate to high caffeine consumers had high levels of state and/or trait anxiety. Also, unlike medical inpatients (Victor et al., 1981) and normal adults (Rapoport et al., 1981), our high consumers did not differ from low consumers in reporting anxiety in response to drinking coffee (although other somatic symptoms tended to develop more in low consumers, similar to previous reports). In other words, in anxiety patients, reporting of anxiety symptoms according to amount of caffeine consumption was different from medical inpatients or normal adults, while the reporting of somatic symptoms according to a mount of caffeine consumption was the same. This pattern suggests that neurobiological mechanisms mediating anxiety may have increased sensitivity to caffeine, whereas mechanisms mediating somatic symptoms may not. It is noteworthy that more PA patients became anxious in response to caffeine than non-PA patients; this deserves further testing in a larger sample to examine whether increased sensitivity to caffeine is characteristic of panic disorder but not other anxiety disorder diagnoses. Boulenger et al. (1984) also reported increased sensitivity to caffeine in panic disorder but not in major depressive disorder.

In contrast to Boulenger et al. (1984), we did not find any significant correlations between amount of caffeine consumption and any of the SCL-90-R subscale scores, probably due at least in part to the narrow range of daily caffeine consumption in most of the anxious patients in this sample. Boulenger et al. (1984) suggested that increased sensitivity to caffeine in panic disorder may not be related to baseline level of anxiety since their depressed patients also had high anxiety levels but did not have increased sensitivity to caffeine. However, the present data comparing anxiety level between caffeine-sensitive and caffeine-nonsensitive patients in the PA group suggested that, within PA patients, a high baseline anxiety level was related to increased sensitivity to caffeine. This difference suggests that the mechanism producing anxiety in depressive disorders may not involve increased sensitivity to caffeine but that in panic disorder it may. This needs to be clarified with future studies. Amount of daily caffeine consumption and increased sensitivity to caffeine in these anxiety patients were consistent with prior results.

The data of this study suggested that in normal adults or in psychiatric inpatients (Gilliland and Andress, 1981; Greden et al., 1978) caffeine may be one of the contributing factors that increases anxiety, but in anxiety disorder patients, caffeine is not one of the significant factors that accounts for their high level of anxiety; rather, high anxiety appears to deter anxious individuals from high caffeine consumption. This probably explains why most anxiety disorder patients were low caffeine consumers. Also, sensitivity to caffeine is not clearly related to amount of daily caffeine consumption, as is the case in normal adults and medical inpatients (Rapoport et al., 1981; Victor et al., 1981); rather, in anxiety disorders, their 
underlying high anxiety level seems to produce high sensitivity to caffeine, even in low doses. Future studies with caffeine challenges using double-blind procedures should provide more precise and quantifiable evidence of the effects of caffeine on anxiety. Caffeine should provide a pharmacological probe with which to study further the pathophysiology of panic and other anxiety disorders.

\section{References}

American Psychiatric Association. DSM-III: Diagnostic and Statistical Manual of Mental Disorders. 3rd ed. APA, Washington, DC (1980).

Boulenger, J.P., Patel, J., and Marangos, P.J. Effects of caffeine and theophylline on adenosine and benzodiazepine receptors in human brain. Neuroscience Letters, 30, 161 (1982).

Boulenger, J.P., Uhde, T.W., Wolff, E.A. III, and Post, R.M. Increased sensitivity to caffeine in patients with panic disorders: Preliminary evidence. Archives of General Psychiatry, 41, 1067 (1984).

Derogatis, L.R. SCL-90-R Manual: I. Scoring and Procedures Manual for the SCL-90-R. Clinical Psychometrics Research Unit, Baltimore (1977).

File, S.E., Bond, A.J., and Lister, R.G. Interaction between effects of caffeine and lorazepam in performance tests and self-ratings. Journal of Clinical Psychopharmacology, 2, 102 (1982).

Gilliland, K., and Andress, D. Ad lib caffeine consumption, symptoms of caffeinism, and academic performance. American Journal of Psychiatry, 138, 512 (1981).

Goldberg, M.R., Curatolo, P.W., Tung, C.-S., and Robertson, D. Caffeine down-regulates $\beta$-adrenoreceptors in rat forebrain. Neuroscience Letters, 31, 47 (1982).

Greden, J., Fontaine, P., Lubetsky, M., and Chamberlin, K. Anxiety and depression associated with caffeinism among psychiatric inpatients. American Journal of Psychiatry, 135, 963 (1978).

Greden, J.F., Victor, B.S., Fontaine, P., and Lubetsky, M. Caffeine-withdrawal headache: A clinical profile. Psychosomatics, 21, 411 (1980).

Mattila, M., Palva, E., and Savolainen, K. Caffeine antagonizes diazepam effects in man. Medical Biology, 60, 121 (1982).

Patwadhan, R., Desmond, P., Johnson, R.F., Dunn, D., Robertson, D.H., Hoyumpa, A. M., and Schenker, S. Effects of caffeine on plasma free fatty acids, urinary catecholamines, and drug binding. Clinical Pharmacology and Therapeutics, 28, 398 (1980).

Polc, P., Bonetti, P., Pieri, L., Cumin, R., Angioi, R.M., Möhler, H., and Haefely, W.E. Caffeine antagonizes several central effects of diazepam. Life Sciences, 28, 2265 (1981).

Rapoport, J., Jensvold, M., Elkins, R., Buchsbaum, M.S., Weingartner, H., Ludlow, C., Zahn, T.P., Berg, C.I., and Neims, A.H. Behavioral and cognitive effects of caffeine in boys and adult males. Journal of Nervous and Mental Disease, 169, 726 (1981).

Robcrtson, D., Frölich, J., Carr, R.K., Watson, J.T., Hollifield, J.W., Shand, D.G., and Oates, J.A. Effects of caffeine on plasma renin activity, catecholamines and blood pressure. New England Journal of Medicine, 298, 181 (1978).

Robertson, D., Wade, D., Workman, R., Wonsley, R.I.., and Oates, J.A. Tolerance to the humoral and hemodynamic effects of caffeine in man. Journal of Clinical Investigation, 67, $1111(1981)$.

Snyder, S., and Sklar, P. Behavioral and molecular actions of caffeine: Focus on adenosine. Journal of Psychiatric Research, 18, 91 (1984).

Uhde, T.W., Boulenger, J.P., Jimerson, D.C., and Post, R.M. Caffeine: Relationship to human anxiety, plasma MHPG and cortisol. Psychopharmacology Bulletin, 20, 426 (1984).

Victor, B., Lubetsky, M., and Greden, J. Somatic manifestations of caffeinism. Journal of Clinical Psychiatry, 42, 185 (1981). 